\title{
Productivity and deadweight losses due to relapses of schizophrenia in Japan
}

This article was published in the following Dove Press journal:

Neuropsychiatric Disease and Treatment

17 May 2017

Number of times this article has been viewed

\author{
Yusuke Nakamura' \\ Jörg Mahlich ${ }^{1,2}$ \\ 'Health Economics, Janssen \\ Pharmaceutical K.K., Tokyo, Japan; \\ ${ }^{2}$ Düsseldorf Institute for Competition \\ Economics (DICE), University of \\ Düsseldorf, Düsseldorf, Germany
}

Background: No study has examined the financial impact of relapses on schizophrenia from the perspective of Japanese society. This study aimed to estimate the societal costs in Japan caused by the relapses of schizophrenia.

Methods: The societal costs in Japan in 2013 due to relapses of schizophrenia were estimated by summing the productivity loss and deadweight loss caused by schizophrenia relapses in 2013. Deterministic sensitivity analysis was conducted for deadweight loss rate, relapse rate, and patient income.

Results: Japan incurred JPY 55,039 million societal costs because of relapses in 2013. This consists of JPY 3,990 million for productivity loss and JPY 51,049 million for deadweight loss. Rate of deadweight loss is the most significant cost driver in the sensitivity analysis.

Conclusion: Relapses of schizophrenia could generate huge amount of societal costs by reducing labor productivity and economic efficiency. To curb these costs, relapse prevention is desired in treating schizophrenia.

Keywords: schizophrenia, relapses, societal costs, productivity loss, deadweight loss, Japan

\section{Background}

Schizophrenia (ICD-10: F20) is a chronic, severe, and disabling brain disorder that significantly impacts a person's thought processes and emotional responsiveness. The disorder usually consists of one or more symptoms such as hallucinations, delusions, disorganized communication, poor planning, reduced motivation, and blunted affect. ${ }^{1-3}$ The prevalence rate in Japan is $\sim 7$ per 1,000 persons, ${ }^{4}$ which is broadly consistent with the mean prevalence rates found in other countries. ${ }^{5}$

Schizophrenia is associated with significant social or occupational dysfunction and reduces a patient's quality of life and ability to engage in everyday activities. A European study of six countries found that $>80 \%$ of adults with schizophrenia had some persistent problems with social functioning, though not all of them were severe. ${ }^{3}$ Mortality rates for people with schizophrenia are 2-3 times higher than in the general population. ${ }^{6,7}$ In addition to the number of deaths directly attributed to schizophrenia, there are a number of people who commit suicide as a result of having the illness. In 2013, the Cabinet Office, Government of Japan, ${ }^{8}$ published the total number of suicides for the year 2012 (28,396). The number of suicides attributable to schizophrenia was 1,150 (617 males and 533 females).

The estimated total cost of schizophrenia in Japan was JPY 2.77 trillion, which was equivalent to US\$23.8 billion. $^{4}$ Of this total, JPY 0.77 trillion (US\$6.59 billion) was the direct cost of health care and social service, and JPY 1.85 trillion (US\$20.2 billion) was the cost of morbidity and mortality. The research indicates that both direct and indirect costs are important cost components in schizophrenia, 
which echoes the findings from other countries. ${ }^{9,10}$ While Sado et $\mathrm{al}^{4}$ calculated the total cost of illness, in this study, the focus was on the specific cost of relapses in schizophrenia in Japan. Information on the cost of relapses would allow for a better understanding of the potential cost savings of relapse prevention that might be achievable through innovations in the health care setting or improved medical adherence. ${ }^{11}$

The authors had particular interest in the aspect of production loss and deadweight loss which has been neglected in previous studies. Productivity and deadweight losses that result from a distortionary impact of taxes on workers' labor and consumption choices are real economic costs in the sense of forgone production. Direct costs on the other hand constitute income for other economic agents such as medical service providers. As such, direct costs are just a redistribution of wealth and do not necessarily create costs from a societal point of view. In accordance with this, the production loss and deadweight loss were estimated as societal costs incurred by schizophrenia relapses in Japan.

\section{Methods}

\section{Availability of data and materials}

All data used in this literature were retrieved from disclosed statistics and published literatures referred to in the reference section. Data were retrieved by a PubMed search as well as a search in official statistics issued by the Japanese gouvernment.

\section{Ethics approval and consent}

This literature does not include data that require obtaining ethical approval. This literature does not include data that require consent from participants.

The societal costs due to schizophrenia relapse in Japan were estimated by using a prevalence approach. Cost components in this study are presented in Table 1. In the study, total societal costs due to schizophrenia relapse consist of productivity and deadweight losses due to relapses that occurred in schizophrenia patients.

The productivity loss refers to income losses due to less employment and premature death. Deadweight loss refers to the economic inefficiency incurred due to raising government funding through taxes that is explained in Figure 1. In the absence of taxes, a market is in equilibrium at the intersection of the supply and demand curve. When taxes $(T)$ are

Table I Cost components

\begin{tabular}{ll}
\hline Type of costs & Definition \\
\hline Productivity loss & $\begin{array}{l}\text { Income losses due to relatively lower employment } \\
\text { and premature mortality }\end{array}$ \\
Deadweight loss & $\begin{array}{l}\text { Loss of economic efficiency due to the government } \\
\text { funding }\end{array}$ \\
\hline
\end{tabular}

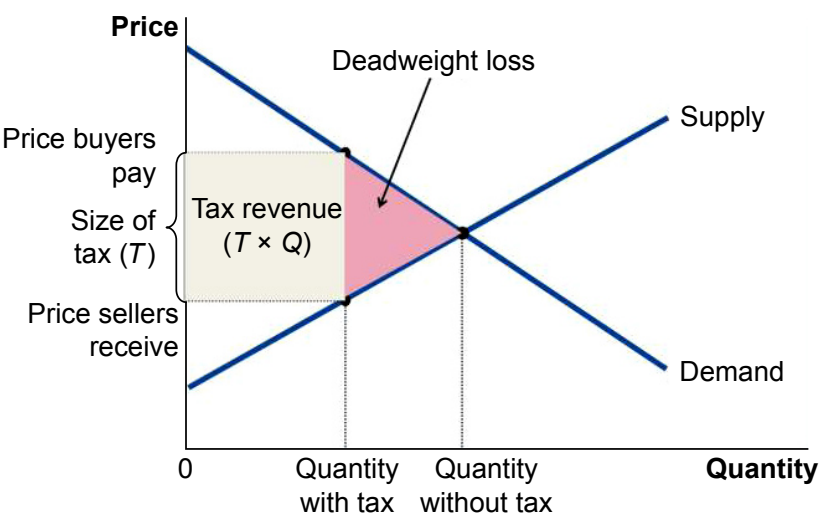

Figure I Deadweight loss.

imposed, rising gross product prices reduce the demand, and declining net product prices lower the supply. The presence of taxes leads to a redistribution of wealth from both customers and firms to the government in the size of $T \times$ Quantity $(Q)$ without tax. A redistribution, however, is not an economic loss because the government can spend this money that will eventually flow back into the economy. The figure also depicts the real economic deadweight loss that results from the reaction of firms and consumers to the price changes that occurred after taxation. This economic loss is due to a reduction of production that cannot be redistributed. Price elasticity of supply and demand determines the size of this deadweight loss. Buyers and suppliers were less sensitive to price with decreasing deadweight loss and greater tax revenue. ${ }^{12}$

\section{Study population}

As a basis of calculating productivity loss and deadweight loss, patients who experienced a relapse were first estimated. Because of data availability, and in line with common practice in existing literature, hospitalization was used as a proxy for relapses in this research and hospitalization data were used as a proxy to measure the number of people who relapsed in Japan. ${ }^{13,14}$ Only non-same day hospitalizations were included in the estimation. According to the 2011 Patient Survey, there were $\sim 0.92 \%$ of hospitalizations that were non-same day. ${ }^{15}$ Applying $0.92 \%$ to the 2011 Patient Survey data and adjusting for population change between 2011 and 2013, the total number of inpatients for ICD-10 code F20 was estimated at $163,219.4,16$ However, in Japan, factors such as easy access to hospitals, lack of community and residential care, financial difficulties, and stigma associated with schizophrenia in the community have contributed to higher rates of hospitalization than in elsewhere. ${ }^{17,18}$ Therefore, using 163,219 as the total number of inpatients would be an overestimate of the number of people who relapsed for the purpose of this report. 
In a research article by Oshima et $\mathrm{al}^{17}$ who investigated the proportion of schizophrenia inpatients that could be discharged, they found that $\sim 40 \%$ were judged to have the possibility of being discharged using community resources. In other words, only $\sim 60 \%$ of existing schizophrenia inpatients were considered hospitalized due to the condition. This $60 \%$ was used to set the number of inpatients who was considered to be hospitalized due to a relapse. As a result, 97,931 patients who experienced a relapse in 2013 were obtained.

The proportions of gender using the prevalence and the number of the patients aged from 20 to 59 years from Sado et $a l^{4}$ were further estimated. Based on this information, it was estimated that there were 47,467 males and 50,464 females.

\section{Lost employment due to relapses}

The productivity losses due to less employment associated with a relapse were based on the difference in employment of people who recently experienced a relapse and people who did not. The employment rates for people with schizophrenia were $21.3 \%$ and $16.3 \%$ for males and females, respectively, based on the average employment rates among patients with schizophrenia aged from 20 to 59 years. ${ }^{4}$ The percentage difference in the probability of employment for people who relapse and people who do not was $26.2 \% .{ }^{19}$ Based on this information, the implied employment rate for people who experienced a relapse was $18.4 \%$ for males and $14.1 \%$ for females in Japan in 2013 . For those who did not experience a relapse, the employment rates were $23.2 \%$ for males and $17.8 \%$ for females. Therefore, it was estimated that the difference in people who experienced a relapse and who did not was $4.8 \%$ (ie, $23.2 \%$ minus $18.4 \%$ ) for males and $3.7 \%$ (ie, $17.8 \%$ minus $14.1 \%$ ) for females in 2013. These rates ( $4.8 \%$ for males and $3.7 \%$ for females) indicate the rate of lost employment due to relapses in 2013. Table 2 summarizes the results of those calculations.

Table 2 Employment rate of people with schizophrenia in 2013

\begin{tabular}{ll}
\hline Population & $\begin{array}{c}\text { Employment } \\
\text { rate (\%) }\end{array}$ \\
\hline All people with schizophrenia & 21.3 \\
$\quad$ Male & 16.3 \\
$\quad$ Female & \\
People who were employed and experienced relapse & 18.4 \\
$\quad$ Male & 14.1 \\
Female & \\
People who would have been employed without relapse & 23.2 \\
$\quad$ Male & 17.8 \\
Female & \\
Difference in people who experienced a relapse and who & \\
have not & 4.8 \\
Male & 3.7 \\
Female &
\end{tabular}

Note: Data from Sado M. ${ }^{4}$

Neuropsychiatric Disease and Treatment 2017:13

\section{Premature deaths due to relapses}

To calculate the productivity loss due to premature deaths with relapse, the number of employed people who commit suicide with relapses was estimated. As discussed in the "Background" section, the number of suicides due to schizophrenia was $\sim 1,150$ (617 for males and 533 for females) in 2012. ${ }^{8}$ It is assumed that people who relapse with schizophrenia have a higher rate of suicide than those who do not. This assumption is based on a systematic review which found that the rate of suicide was almost 4 times greater for those not adhering to medication compared to those who did. ${ }^{20}$ Therefore, it was further assumed that $80 \%$ of suicides were attributed to schizophrenia relapse. The total number of suicides due to relapse was estimated at 920 by applying $4 / 5(80 \%)$ to the total 1,150 suicides. As not all of those people who committed suicide would have been employed, the employment rate of people with relapse was applied to this.

\section{Patient income}

The productivity losses were calculated by multiplying the sum of lost employment and premature death by the yearly income of schizophrenia patients. According to the Survey on the Employment Situation of Persons with Disabilities 2008, the salary of people with schizophrenia was $\sim$ JPY 53,000 per month. ${ }^{21}$ Adjusting for wage growth, the salary of people with schizophrenia in 2013 was $\sim$ JPY 55,698 per month. ${ }^{22-24}$ The low salary earned by people with schizophrenia is due to the fact that a significant proportion worked as part-time employees. In fact, among those who were employed, $92.5 \%$ worked between 20 and 30 hours a week, ie, 4 to 5 hours a day. ${ }^{21}$ On the other hand, according to the report of National Tax Agency, the national average salary per person was JPY 345,000 per month in $2013 .{ }^{25}$ Therefore, the authors applied JPY 55,698 to $92.5 \%$ and JPY 345,000 million to $7.5 \%$, obtaining JPY 77,396 as an average monthly salary of schizophrenia patients in 2013.

\section{Deadweight loss due to relapses}

Much of the direct health care system costs, prison costs, and social security (transfer) payments associated with a schizophrenia relapse are funded by the government. This requires the government to increase tax revenue in order to achieve a budget-neutral position. Taxes and transfers (such as subsidies and pensions) do not themselves represent a real economic cost. This is because they are payments from one economic agent to another, and therefore do not involve the use of actual resources. However, the cost of raising revenue to fund transfer payments is not frictionless as a tax reduces the efficiency with which the economy's resources are used. Such a distortion represents the concept of deadweight loss. 
To estimate the deadweight loss on schizophrenia relapses, the authors considered a deadweight loss that occurred due to government taxation to raise funds to finance unemployment benefits and direct health system costs.

Should a working person with schizophrenia become unemployed, he/she may be eligible for unemployment benefits. The duration of benefits is limited to a certain period of time, usually 3 months to a year. This will depend on the length of employment and the age of the worker. Furthermore, the benefit is usually capped at JPY 350,000 per month. ${ }^{26}$ It was assumed that each unemployed regular worker received an unemployment benefit for a period of 6 months at $80 \%$ of the average monthly salary (JPY 77,396). In the previous section, it was estimated that 4,416 people were unemployed due to relapse and $4.7 \%$ of them were considered regular workers, ${ }^{24}$ where a regular worker is generally covered under public insurance systems including workers' compensation, unemployment benefit, health care, and retirement pension. ${ }^{27}$

JPY 602,771 million was used as the inpatient direct costs of schizophrenia in Japan. ${ }^{4}$ However, not all hospitalization costs are attributable to schizophrenia relapses. This would depend on the number of patients who are considered to be suffering from relapses. Therefore, the assumption of $60 \%$ relapse was applied to the value.

To estimate the deadweight loss, the proportions of governmental funding and deadweight loss rate were applied to the value of unemployment benefit and direct health system costs. The proportion of direct health system costs borne by the government and health insurance was $88.2 \%$ derived from an estimation of national medical care expenditure in $2013 .{ }^{28}$ Internationally, it has been reported that deadweight loss rates are estimated to be in the range of $9 \%-16 \%$ and $50 \%{ }^{29}$ To be conservative and consistent with Roberts et al, ${ }^{30}$ a lower end parameter estimate of $16 \%$, which is based on US data, is used to calculate the deadweight loss of raising additional taxation revenue to finance government costs associated with schizophrenia relapse in Japan.

\section{Sensitivity analysis}

A deterministic sensitivity analysis was performed to test the robustness of estimation of this study and identify influential factors on societal costs due to relapses of schizophrenia. Several parameters including the relapse rate of schizophrenia, deadweight loss rate, and patient income per month were examined.

Because of the limitation in data availability, it was assumed that $42 \%(-30 \%)$ is a lower bound and $78 \%(+30 \%)$ is an upper bound on the relapse rate on schizophrenia. Based
Table 3 Employment of people with schizophrenia in 2013

\begin{tabular}{|c|c|c|}
\hline & Employment rate (\%) & Employment (n) \\
\hline \multicolumn{3}{|c|}{ Patients who were employed assuming $60 \%$ relapse in 2013} \\
\hline Male & 18.4 & 16,075 \\
\hline Female & 14.1 & 13,104 \\
\hline Total & & 29,179 \\
\hline \multicolumn{3}{|c|}{$\begin{array}{l}\text { Patients who would have been employed if there had been no relapse } \\
\text { in } 2013\end{array}$} \\
\hline Male & 23.2 & 18,354 \\
\hline Female & 18.4 & $|4,97|$ \\
\hline Total & & 33,325 \\
\hline \multicolumn{3}{|c|}{$\begin{array}{l}\text { Difference in employment of people who experienced a relapse and } \\
\text { people who have not }\end{array}$} \\
\hline Male & 4.8 & 2,279 \\
\hline Female & 4.3 & $\mathrm{I}, 867$ \\
\hline Total & & 4,146 \\
\hline
\end{tabular}

on the range obtained from Roberts et al, ${ }^{30} 9 \%$ was applied as a lower bound and $50 \%$ as an upper bound on the deadweight loss rate. For the monthly patient income, JPY 55,698 estimated by survey for people with disabilities ${ }^{21}$ was used as a lower bound and JPY 345,000 estimated by average salary in overall population ${ }^{25}$ as an upper bound.

\section{Results}

\section{Productivity loss due to relapses}

Applying the employment rates to the number of persons who relapsed gives the number of people who were employed assuming $60 \%$ relapse $(29,179)$, and the number of people who would have been employed if no patient had relapsed $(33,325)$. Comparing these two numbers, there are 4,146 people unemployed at any one time due to a relapse under the base case. Table 3 presents these findings.

Using the employment rate with relapse (ie, 18.4\% for males and $14.1 \%$ for females), it was estimated that 151 out of 920 people who committed suicide would have been employed.

As a total, 4,297 members of the labor force were lost because of lower employment and premature death due to relapse in 2013. Applying the JPY 77,396 as the monthly salary of people with schizophrenia, the total productivity loss was estimated to be JPY 3,990 million in 2013. Table 4 presents the results on the total productivity lost because of relapses in 2013.

Table 4 Total productivity loss due to relapses in 2013

\begin{tabular}{ll}
\hline & Amount \\
\hline Labor lost due to the unemployment $(A)$ & 4,146 patients \\
Labor lost due to the premature death (B) & I5I patients \\
Total labor lost $(A+B)$ & 4,297 patients \\
Total productivity loss $(A+B) \times$ salary & $¥ 3,990$ million \\
\hline
\end{tabular}


Table 5 Total deadweight loss due to relapses in 2013

\begin{tabular}{ll}
\hline & $\begin{array}{l}\text { Amount } \\
\text { (million JPY) }\end{array}$ \\
\hline Fund required for unemployment benefit (A) & 72 \\
Fund required for direct health system costs (B) & 318,986 \\
Total fund required $(\mathrm{A}+\mathrm{B})$ & 319,059 \\
Total deadweight loss $(\mathrm{A}+\mathrm{B}) \times 16 \%$ & 51,049 \\
\hline
\end{tabular}

Table 6 Total societal costs due to relapses in 2013

\begin{tabular}{ll}
\hline & $\begin{array}{l}\text { Amount } \\
\text { (million JPY) }\end{array}$ \\
\hline Total productivity loss (A) & 3,990 \\
Total deadweight loss (B) & 51,049 \\
Total costs (A + B) & 55,039 \\
\hline
\end{tabular}

\section{Deadweight loss due to relapses}

It was estimated that a total of JPY 72 million in transfers were made to fund unemployment benefit because of relapse in 2013. To estimate this, it was assumed that $4.7 \%$ of unemployed patients received unemployment benefit at the level of $80 \%$ income for 6 months. A rate of full-time worker, average income, guaranteed salary rate under the benefit, and duration of the benefit were further applied to the number of employed patients due to relapse. Therefore, the fund required for unemployment benefit was calculated as 4,416 patients $\times 4.7 \% \times$ JPY $77,396 \times 80 \% \times 6$ months, resulting in JPY 72 million.

It was estimated that JPY 318,986 million was funded to direct health system from public expenditure because of relapses. This was calculated as a product of inpatient direct costs of schizophrenia, rate of relapse, and rate of public funding. The calculation was JPY 602,771 million $\times 60 \% \times$ 0.882 , resulting in JPY 318,986 million.

Finally, JPY 51,049 million was obtained as a total deadweight loss. This was estimated by applying deadweight loss rate to the total fund required because of relapses. The calculation process was [72 million $+318,986$ million $] \times 16 \%$. Table 5 presents the summary results of deadweight loss.

\section{Total societal costs due to relapses}

Table 6 presents the total costs based on the estimations of this study. Adding the total productivity loss and total deadweight loss, JPY 55,039 million was obtained as the total societal costs due to relapses on schizophrenia in 2013.

\section{Sensitivity analysis}

Table 7 and Figure 2 present the summary results of the deterministic sensitivity analysis. It was found that the driving factor of total costs was deadweight loss rate based on these results. On the other hand, lower monthly patient income and higher relapse rate did not impact the total societal cost so much.

Total societal costs on relapse rate ranged from JPY 51,049 million to JPY 55,415 million. Total societal costs on deadweight loss rate ranged from JPY 32,706 million to JPY 163,520 million. Total societal costs on monthly patient income ranged from JPY 53,921 million to JPY 68,837 million.

\section{Discussion}

Costs incurred by relapses of schizophrenia in Japan were substantial in 2013. The total societal cost was JPY 55,040 million: JPY 3,990 million for productivity loss and JPY 51,040 million for deadweight loss. The deadweight loss amount was much more substantial, which underlines the need to include this cost component in the calculation of burden of disease studies. Deterministic sensitivity analysis suggested that the major cost driver is a degree of distortionary impact. The novelty of this research is a focus on societal costs due to relapses on schizophrenia and the first introduction of the deadweight loss. As far as the authors know, in Japan, there is no existing study that estimates relapse costs of schizophrenia.

In order to reduce and avoid these societal losses, the importance of relapse prevention should be embraced in clinical practices and policy making. Potential solutions could include medication with better adherence such as long-acting injectable antipsychotics (LAIs), because evidence suggests that LAIs improve patient adherence and eventually reduce hospital stays. ${ }^{31-34}$ A recent Japanese claims database analysis for instance concluded that LAIs were associated with a reduction of emergency room visits $(-44 \%)$ and rehospitalizations $(-62 \%) .{ }^{35}$ In spite of higher acquisition costs, several costeffectiveness studies demonstrated economic superiority of LAIs over oral antipsychotics even though they do not take indirect costs into consideration. ${ }^{36-38}$ Another option could

Table 7 Variations for detreministic sensitivity analysis

\begin{tabular}{|c|c|c|c|c|c|}
\hline \multirow[t]{2}{*}{ Parameters } & \multirow{2}{*}{$\begin{array}{l}\text { Base case } \\
\text { Base value }\end{array}$} & \multicolumn{2}{|c|}{ Sensitivity analysis case } & \multicolumn{2}{|c|}{ Results in sensitivity analysis } \\
\hline & & Lower bound value & Upper bound value & Lower bound value & Upper bound value \\
\hline Relapse rate & $60 \%$ & $42 \%$ & $78 \%$ & $¥ 26,494$ million & $¥ 26,82$ I million \\
\hline Deadweight loss rate & $16 \%$ & $9 \%$ & $50 \%$ & $¥ 16,622$ million & $¥ 74$, I 67 million \\
\hline Monthly income & $¥ 77,396$ & $¥ 55,698$ & $¥ 345,000$ & $¥ 25,328$ million & $¥ 40,244$ million \\
\hline
\end{tabular}




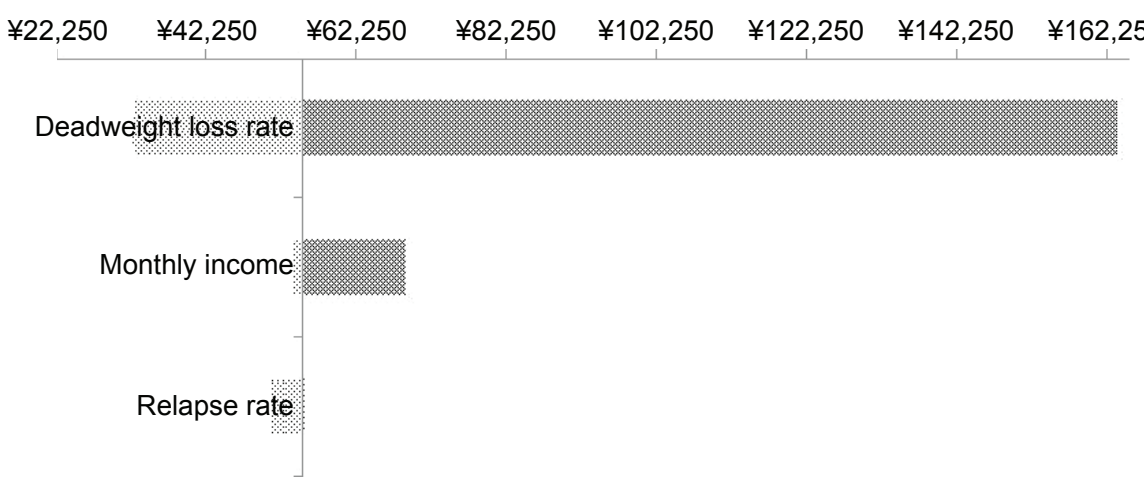

Figure 2 Tornado chart deterministic sensitivity analysis.

be the community-based treatment of schizophrenia. Several international studies indicate that, combined with psychosocial education, community care in treating schizophrenia could improve patient outcomes such as continuity of treatment, number of hospitalization, duration of hospital stay, socioeconomic status, and patient satisfaction. ${ }^{39-41}$ For Japan, a recent Japanese study evaluated a program that encouraged hospitals to discharge patients into the community with the support of an assigned worker. The results indicated that the majority (79\%) of patients successfully reintegrated into the community. ${ }^{41}$

This kind of evidence has led the Japanese Ministry of Health, Labour and Welfare (MHLW) to promote the integrated community care system in caring for patients with mental disorders in Japan by changing public awareness of mental disorders, reforming a health care system in psychiatric care, reconstructing a system for community-care support, and enhancing the basis of mental health policies. ${ }^{42-44}$ For example, MHLW is implementing cross-sector measures to assign more human resources in community care, improve treatment discontinuation, and promote early intervention for mental disorders. ${ }^{45}$ In addition, MHLW is financially incentivizing community care by improving medical fee schedule for community transition and visiting nurse. ${ }^{46}$

Some scholars, however, fear that those attempts could lead to discharges without proper discharge planning. ${ }^{47}$ According to this study, discharge planning was associated with shorter length of hospital stay. In clinical practices, cross-functional discharge planning is embedded as one of the requirements to receive a medical fee for discharge support and community transition..$^{42,44}$

Finally, when putting the cost estimates in a context with other diseases in Japan, the indirect costs of relapses caused by schizophrenia (JPY 55,040 million) seem to be higher than the indirect costs of alcohol misuse (JPY 5,338 million) ${ }^{48}$ but lower than those for prostate cancer (JPY 87,900 million) ${ }^{49}$ or stomach cancer (JPY 889,500 million). ${ }^{50}$
There are several limitations in this research. These include: 1) only international rates were applied, in particular the authors relied on an US study to estimate the deadweight loss that turned out to be the biggest cost driver; 2) this study does not include an impact of presenteeism; and 3) this study does not consider the indirect costs of caregivers. Further research on the distortionary impacts is desired to more accurately and comprehensively estimate the societal cost of schizophrenia in Japan.

\section{Conclusion}

Societal costs of relapse in schizophrenia are substantial in Japan. The findings of the study highlight the emerging needs of relapse-preventive intervention for schizophrenia to reduce societal costs in Japan.

\section{Acknowledgments}

The authors would like to express their gratitude to Mitsuhiro Sado, an assistant professor of Neuropsychiatry Department, School of Medicine, Keio University, for his inputs. The Janssen Pharmaceutical K.K funded this study through the authors' researcher position at the company.

\section{Author contributions}

Both authors contributed toward data analysis, drafting and critically revising the paper and agree to be accountable for all aspects of the work.

\section{Disclosure}

YN and JM are employed at Janssen Pharmaceutical KK. The authors report no other conflicts of interest in this work.

\section{References}

1. Saha S, Chant D, Welham J, McGrath J. A systematic review of the prevalence of schizophrenia. PLoS Med. 2005;2(5):e141.

2. The National Institute of Mental Health (NIMH). Schizophrenia. US Department of Health and Human Services. Bethesda; 2009. Available from https:/www.nimh.nih.gov/health/publications/schizophreniabooklet/index.shtml. Accessed July 27, 2016. 
3. National Collaborating Centre for Mental Health (NCCMH). Schizophrenia: the NICE guideline on core interventions in the treatment and management of schizophrenia in adults in primary and secondary care, Commissioned by the National Institute for Health \& Clinical Excellence, National Clinical Guideline No. 82. London; 2010.

4. Sado M, Inagaki A, Koreki A, et al. The cost of schizophrenia in Japan. Neuropsychiatr Dis Treat. 2013;9:787-798.

5. Schizophrenia.com. Schizophrenia Facts and Statistics. Available from: http://www.schizophrenia.com/szfacts.htm\#. Accessed July 27, 2016.

6. Auquier P, Lancon C, Roulillon F, Lader M, Holmes C. Mortality in schizophrenia. Pharmacoepidemiol Drug Saf. 2006;15:873-879.

7. Saha S, Chant D, McGrath J. A systematic review of mortality in schizophrenia. Arch Gen Psychiatry. 2007;64(10):1123-1131.

8. Cabinet Office, Government of Japan. Situation of suicide in 2012. Appendix 1, Number of suicides by cause/attribution by age, Tokyo; 2013. Available from: http://www.mhlw.go.jp/file/06-Seisakujouhou12200000-Shakaiengokyokushougaihokenfukushibu/h2412.pdf. Accessed July 27, 2016. Japanese.

9. Phanthunane P, Whiteford H, Vos T, Bertram M. Economic burden of schizophrenia: empirical analyses from a survey in Thailand. $J$ Ment Health Policy Econ. 2012;15(1):25-32.

10. Jin H, Mosweu I. The societal cost of schizophrenia: a systematic review. Pharmacoeconomics. 2017;35:25-42.

11. Kuwabara H, Saito Y, Mahlich J. Adherence and e-hospitalizations in patients with schizophrenia: evidence from Japanese claims data. Neuropsychiatr Dis Treat. 2015;11:935-940.

12. Mankiv G. Principles of Economics. Thomson: Mason, OH; 2007.

13. Deloitte Access Economics. The cost of relapse in Australia: and the potential to improve health outcomes and avoid costs using long-acting antipsychotic injection, Report for Janssen-Cilag Pty Limited; 2011.

14. Olivares JM, Sermon J, Hemels M, Schreiner A. Definitions and drivers of relapse in patients with schizophrenia: a systematic literature review. Ann Gen Psychiatry. 2013;12:32.

15. Ministry of Health, Labour and Welfare (MHLW). 2011 Patient Survey, Tokyo; 2012. Available from: http://www.mhlw.go.jp/english/database/ db-hss/sps_2011.html. Accessed July 27, 2016.

16. National Institute of Population and Social Security Research (NIPSSA). Population projection for Japan: 2006-2055, Tokyo; 2006. Available from: http://www.ipss.go.jp/index-e.asp. Accessed July 27, 2016.

17. Oshima I, Kuni E. Living arrangements of individuals with schizophrenia in Japan: impact of community-based mental health services. Int J Soc Psychiatry. 2006;52(1):55-64.

18. Hopper K, Harrison G, Janca A, Sartorius N, eds. Recovery from Schizophrenia: An International Perspective. A Report from the WHO Collaborative Project, the International Study of Schizophrenia. Oxford: Oxford University Press; 2007.

19. Hong J, Windmeijer F, Novick D, Haro JM, Brown J. The cost of relapse in patients with schizophrenia in the European SOHO (Schizophrenia Outpatient Health Outcomes) study. Prog Neuropsychopharmacol Biol Psychiatry. 2009;33:835-841.

20. Hawton K, Sutton L, Haw C, Sinclair J, Deeks JJ. Schizophrenia and suicide: systematic review of risk factors. $B r J$ Psychiatry. 2005; 187:9-20.

21. Ministry of Health, Labour and Welfare (MHLW). Survey on the Employment Situation of Persons with Disabilities, Table 3-18, Salary of psychiatric disorder patients by disease, severity and expected weekly working hours and Table 3-16, Distribution working hours among psychiatric disorder patients by disease, severity and expected weekly working hours (2008), Tokyo; 2009. Available from: http://www. mhlw.go.jp/stf/houdou/2r98520000002fxj-img/2r98520000002g75. pdf. Accessed July 29, 2016.

22. Statistics Bureau Japan. Consumer price index. Tokyo; 2013. Available from: http://www.stat.go.jp/english/data/cpi/. Accessed July 29, 2016.

23. Statistics Bureau Japan. Labour force survey. Tokyo; 2013. Available from: http://www.stat.go.jp/english/data/roudou/results/month/index. htm. Accessed July 29, 2016.
24. Statistics Bureau Japan. Japan statistical yearbook. Tokyo; 2013. Available from: http://www.stat.go.jp/english/data/nenkan/index.htm. Accessed July 29, 2016

25. National Tax Agency. Projections and planning investigation of payroll in private sector. Tokyo; 2014. Available from: https://www.nta.go.jp/ kohyo/tokei/kokuzeicho/minkan2013/pdf/001.pdf. Accessed August 5, 2016.

26. Japan Management Consulting (JMC). Labor insurance in Japan. Tokyo; 2016. Available from: http://www.japan-payroll.com/labor-insurancein-japan. Accessed August 5, 2016.

27. Asao Y. Overview of non-regular employment in Japan. The Japan Institute for Labour Policy and Training (JILPT). Tokyo; 2011. Available from: http://www.jil.go.jp/english/reports/documents/jilpt-reports/ no.10_japan.pdf. Accessed August 5, 2016.

28. Ministry of Health, Labour and Welfare (MHLW). Summary results in estimation of National Medical Care Expenditure in 2013. Tokyo; 2015. Available from: http://www.mhlw.go.jp/toukei/saikin/hw/k-iryohi/13/ dl/kekka.pdf. Accessed August 5, 2016.

29. Stuart C. Welfare costs per dollar of additional tax revenue in the United States. Am Econ Rev. 1984;74(3):352-362.

30. Roberts CB, Hiratsuka Y, Yamada M, et al. Economic cost of visual impairment in Japan. Arch Ophthalmol. 2010;128(6):766-771.

31. Tiihoen J, Haukka J, Taylor M, Haddad PM, Patel MX, Korhonen P. A nationwide cohort study of oral and depot antipsychotics after first hospitalization for schizophrenia. Am J Psychiatry. 2011;168(6): 603-609.

32. Grimaldi-Bensouda L, Rouillon F, Astruc B, et al. Does long-acting injectable risperidone make a difference to the real-life treatment of schizophrenia? Results of the cohort for the general study of schizophrenia (CGS). Schizophr Res. 2012;134(2-3):187-194.

33. Leucht C, Heres S, Kane JM, Kissling W, Davis JM, Leucht S. Oral versus depot antipsychotic drugs for schizophrenia - a critical systematic review and meta-analysis of randomised long-term trials. Schizophr Res. 2011;127(1-3):83-92.

34. Rossi G, Frediani S, Rossi R, Rossi A. Long-acting antipsychotic drugs for the treatment of schizophrenia: use in daily practice from naturalistic observations. BMC Psychiatry. 2012;12:122.

35. Cheung S, Hamuro Y, Mahlich J, Nakahara T, Sruamsiri R, Tsukazawa S. Drug utilization, comorbidities, and resource utilization of Japanese patients with schizophrenia. Clin Drug Invest. 2017;37:559-569.

36. Olivares J, Rodriguez-Martinez A, Burón J, Alonso-Escolano D, Rodriguez-Morales A; e-STAR Study Group. Cost-effectiveness analysis of switching antipsychotic medication to long-acting injectable risperidone in patients with schizophrenia: a 12- and 24-month follow-up from the e-STAR database in Spain. Appl Health Econ Health Policy. 2008;6(1):41-53.

37. Zeidler J, Mahlich J, Greiner W, Heres S. Cost-effectiveness of paliperidone palmitate for the treatment of schizophrenia in Germany. Appl Health Econ Health Policy. 2013;11(5):509-521.

38. Mahlich J, Nishi M, Saito Y. Modelling the budget impact of long acting injectable paliperidone palmitate in the treatment of schizophrenia in Japan. Clinicoecon Outcomes Res. 2015;7:267-272.

39. Karow A, Reimer J, König H, et al. Cost-effectiveness of 12-month therapeutic assertive community treatment as part of integrated care versus standard care in patients with schizophrenia treated with quetiapine immediate release (ACCESS trial). J Clin Psychiatry. 2012; 73(3): $402-\mathrm{e} 408$.

40. Ingram G, Muirhead D, Harvey C. Effectiveness of community treatment orders for treatment of schizophrenia with oral or depot antipsychotic medication: changes in problem behaviours and social functioning. Aust N Z J Psychiatry. 2009;43(11):1077-1083.

41. Aguglia E, Pascolo-Fabrici E, Bertossi F, Bassi M. Psychoeducational intervention and prevention of relapse among schizophrenic disorders in the Italian community psychiatric network. Clin Pract Epidemiol Ment Health. 2007;3:7.

42. Noda F, Clark C, Terada H, et al. Community discharge of patients with schizophrenia: a Japanese experience. Psychiatr Rehabil J. 2004; 28(2):143-149. 
43. Ministry of Health, Labour and Welfare (MHLW). Vision of reforming mental health care and welfare. Tokyo; 2009. Available from: http:// www.mhlw.go.jp/kokoro/nation/area.html. Accessed January 6, 2017.

44. Ministry of Health, Labour and Welfare (MHLW). About the integrated community care system. Tokyo; 2009. Available from: http://www. mhlw.go.jp/bunya/shakaihosho/seminar/d1/02_98-02.pdf. Accessed January 6, 2017.

45. Ministry of Health, Labour and Welfare (MHLW). Summary of change in medical fee schedule in H28. Tokyo; 2016. Available from: http://www.mhlw.go.jp/file/06-Seisakujouhou-12400000Hokenkyoku/0000115977.pdf. Accessed January 6, 2017.

46. Ministry of Health, Labour and Welfare (MHLW). Guidance of supporting establishment of patients' lives in a community. Tokyo; 2015. Available from: http://www.mhlw.go.jp/kokoro/docs/nation_area_01. pdf. Accessed January 6, 2017.
47. Nakanishi M, Niimura J, Tanoue M, Yamamura M, Hirata T, Asukai N. Association between length of hospital stay and implementation of discharge planning in acute psychiatric inpatients in Japan. Int J Ment Health Syst. 2015;9:23.

48. Nakamura K, Tanaka A, Takano T. The social cost of alcohol abuse in Japan. J Stud Alcohol. 1993;54:618-625.

49. Kitazawa T, Matsumoto K, Fujita S, Seto K, Hanaoka S, Hasegawa T. Cost of illness of the prostate cancer in Japan - a time-trend analysis and future projections. BMC Health Serv Res. 2015;15:453.

50. Haga K, Matsumoto K, Kitazawa T, Seto K, Fujita S, Hasegawa T. Cost of illness of the stomach cancer in Japan - a time trend and future projections. BMC Health Serv Res. 2013;13:283.

\section{Publish your work in this journal}

Neuropsychiatric Disease and Treatment is an international, peerreviewed journal of clinical therapeutics and pharmacology focusing on concise rapid reporting of clinical or pre-clinical studies on a range of neuropsychiatric and neurological disorders. This journal is indexed on PubMed Central, the 'PsycINFO' database and CAS, and is the official journal of The International Neuropsychiatric Association (INA). The manuscript management system is completely online and includes a very quick and fair peer-review system, which is all easy to use. Visit http://www.dovepress.com/testimonials.php to read real quotes from published authors.

\footnotetext{
Submit your manuscript here: http://www.dovepress.com/neuropsychiatric-disease-and-treatment-journal
} 